\title{
E-commerce: Experiência de Algumas Empresas de Polímeros
}

\begin{abstract}
Os últimos três anos foram decisivos para a adesão das empresas à internet. A presente matéria é uma tentativa de buscar uma visão geral do que as empresas brasileiras de polímeros estão fazendo para utilizar essa nova ferramenta eletrônica de trabalho. A revista agradece a colaboração das empresas que viabilizaram a realização deste trabalho.
\end{abstract}

$\mathrm{O}$ ingresso na internet generalizou-se a ponto de causar estranheza o fato de alguém não ter um espaço próprio na rede. Num primeiro momento, nota-se uma preocupação geral das empresas em ter seu próprio site, de disponibilizar informações institucionais e técnicas sobre os produtos oferecidos. Este é o lugar comum, o ponto de partida. A seguir, passam a ser oferecidos serviços personalizados, como assistência técnica e informações para agilizar a tomada de decisões e ajudar na solução de problemas.

No Brasil, o ano 2000 foi extremamente significativo. Várias empresas começaram a oferecer seus serviços pela internet a alguns clientes. Um início cauteloso, de testes, com ajustes, para que não se tivesse o efeito contrário ao desejado, pois uma coisa é disponibilizar informações, outra é oferecer serviços e facilidades. Tudo tem que funcionar melhor do que antes, pelo sistema tradicional de catálogos, telefone e fax. Afinal, as revistas publicam regularmente matérias sobre expectativas frustradas e casos mal resolvidos ocorridos em países desenvolvidos, e não se pode cair nos mesmos erros, sob pena de demonstrar incompetência e mesmo fazer o novo sistema cair em descrédito.

Algumas empresas contatadas pela revista gentilmente se dispuseram a passar um pouco da experiência que estão tendo com o comércio eletrônico, umas ainda bem no início, outras já com evidentes sinais de que estão no caminho certo. Todas, porém, com um ponto em comum: o ano 2000 foi o ponto de partida.

Foram colocadas para a GE Plastics South America, DSM South America, Polibrasil Resinas e Ciba Especialidades Químicas questões como: - a data de início das atividades de e-commerce; como o setor está estruturado funcionalmente e a ordem de grandeza dos investimentos; - de onde partiu o know-how para sua organização; - o percentual já realizado de vendas on line e as expectativas futuras; - o papel do e-commerce em relação ao sistema tradicional de vendas; - o nível das informações técnicas do produto disponibilizadas ao cliente; - a relação da empresa com os clientes da internet; a adaptação do consumidor; - as facilidades do e-commerce para o comprador; - a competitividade entre os fornecedores. Os relatos que seguem são resumos das informa- ções fornecidas e ao mesmo tempo fortes indicadores do esforço das empresas, tanto do Brasil como do exterior, de criar meios para utilizar todo o potencial da internet.

\section{www.polibrasil.com.br}

Segundo Ana Laura Sivieri, coordenadora de Marketing e Comunicação, a Polibrasil Resinas disponibilizou para os seus clientes, no final de 2000, uma moderna e eficiente ferramenta, o "E@sy Prolen", o serviço de atendimento on line que permite ao cliente acompanhar o andamento do seu pedido passo a passo, facilitando ainda mais o controle do estoque e dando, em tempo real, acesso direto às informações sobre a empresa que estão dentro dos computadores da Polibrasil. O E@sy Prolen fica no site - www.polibrasil.com.br e o cliente pode acessá-lo através de uma senha que lhe é disponibilizada. Através do E@sy Prolen o cliente tem conhecimento detalhado de tudo que acontece com os seus pedidos, desde o momento em que eles entram nos computadores até a entrega, passando pela nota fiscal, a transportadora, a duplicata, etc. As vantagens são o 
menor custo, mais rapidez e informações em tempo real, a qualquer hora do dia ou da noite, inclusive aos sábados, domingos e feriados.

A Polibrasil não possui um departamento exclusivo para o ecommerce. O que existe é um grupo composto por pessoas de diversas áreas da empresa que desenvolvem também este trabalho, além de suas atividades normais. Não se utilizou experiência de outras empresas para desenvolver o e-commerce; partiuse da análise da necessidade de se ter uma comunicação mais rápida $\mathrm{e}$ eficiente com a Polibrasil. Nessa primeira fase do projeto, os clientes ainda não efetivam a compra pelo e-commerce, mas já acompanham o andamento do pedido. Pretende-se, na segunda fase, completar o processo e o cliente poderá efetivamente comprar pela Internet. O E@sy Prolen é uma inovação e um complemento dos processos tradicionais de vendas que acarreta em uma redução de custos. O nível de aceitação tem sido excelente e à medida que for disponibilizado para todos os clientes poder-se-á mensurar melhor o nível de utilização. Quando se começou a implantação do E@sy Prolen deparou-se com muitas empresas, não apenas pequenas e micros, que ainda não estão estruturadas para utilização desta ferramenta, com poucos usuários tendo acesso à Internet. Na fase atual do programa, a grande vantagem do ecommerce tem sido a agilidade no processo de acompanhamento da venda.

\section{wWw.dsmna.com}

No caso da DSM South America a situação não é muito di- ferente, segundo Dirceu Feijó, gerente de marketing e responsável pelo e-commerce da empresa no Brasil. As atividades se iniciaram há menos de um ano, não existe um departamento específico, mas uma pessoa responsável pelas diretrizes no estabelecimento do e-commerce nas várias divisões de negócios que compõem a DSM. As divisões estão montando times que, além de desenvolver suas tarefas normais, dedicam parte do tempo ao desenvolvimento de e-commerce. Ao contrário da Polibrasil, a DSM está trabalhando em conjunto com outros grandes fabricantes de elastômeros no mundo, e os testes piloto devem ser iniciados no primeiro trimestre de 2001. Feijó acredita que um dos grandes atrativos dessa nova modalidade de comércio seja a redução dos custos operacionais atrelado à agilidade na entrega. Embora o preço seja um fator de mercado, com toda certeza deverá haver redução de custos em ambas as pontas e o e-commerce deve ser um instrumento muito útil para aqueles clientes que não demandam serviços adicionais (embalagens e entregas especiais, desenvolvimento de novos produtos, assistência técnica, etc.) Quanto mais commodity for um produto, mais o e-commerce vai beneficiar sua comercialização, pois a rede aumenta a competitividade e menores serão os diferenciais entre os concorrentes.

\section{www.cibasc.com}

"Algumas pessoas pensam que o e-business será apenas mais uma moda e que não irá trazer grandes impactos ao negócio das empresas, mas outros negócios." Segundo
Eloísio Abreu, responsável pelo $E$ Business na América do Sul, da Divisão Aditivos, "a CIBA acredita que o único erro que podemos cometer é o de ficar parado ou indiferente ao e-business e, mais do que nunca, temos que nos mover na direção certa."

Em janeiro de 2000, o comitê mundial de Internet, centralizado na Suíça, e nomeou um coordenador por país/divisão para implementação do projeto de e-commerce denominado mybusiness@cibasc. Através do site www.cibasc.com, clientes e potenciais clientes, mediante senha, poderão acessar de qualquer lugar do mundo a mesma página e os mesmos serviços, 24 horas por dia, 7 dias por semana. $\mathrm{O}$ sistema permitirá a colocação de pedidos via internet, oferecendo a praticidade de uma lista personalizada dos produtos, facilitando assim sua digitação. Os clientes não só poderão colocar e acompanhar seus pedidos de qualquer uma das divisões on-line, como também terão acesso a uma variedade de informações sobre produtos, tais como folha de dados de segurança, certificados de análise e informações técnicas. Estas informações podem ser dirigidas a todas as pessoas que trabalham nas organizações dos clientes, como compradores, produção ou laboratórios. Com a integração existente entre o e-business e o sistema de gestão operacional da Ciba (ERP), o cliente poderá, via mybusiness@cibasc, fazer o acompanhamento de todos os seus pedidos, não importando se tenha sido colocado por fax, telefone ou internet.

A empresa fez uma projeção de capacidade (servidor, discos, etc.) para manipular um grande volume de pedidos/informações da internet. O lançamento está sendo feito por 
país e enquanto Europa e Estados Unidos começaram em out./nov. de 2000, no Brasil começará em março de 2001. O foco principal não são os custos, mas sim o oferecimento de mais um canal de contato com o cliente, visando melhorar cada vez mais esse relacionamento através de serviços que proporcionem maior facilidade, agilidade e disponibilidade de informações. De acordo com os países que já estão com o sistema operando, a maior parte dos acessos têm sido feitos para o acompanhamento dos pedidos e busca de informações sobre produtos da Ciba. No Brasil, o que pode atrapalhar um pouco é a parte da infra-estrutura de telecomunicações, pois as estruturas telefônicas antigas de algumas regiões acarretam lentidão de acesso à internet.

Para Eloísio Abreu, utilizar a internet é uma questão cultural que vem se alterando dia a dia e que tem despertado o interesse dos clientes. O foco da solução do ecommerce da Ciba é justamente oferecer a colocação de pedidos aos clientes médios e pequenos, pois as contas grandes tendem a se direcionar para o B2B com ligação entre os sistemas de gestão operacional. Quanto ao aumento da competitividade entre os fornecedores em decorrência do uso da rede, destacou que não se deve esquecer que a qualidade dos produtos, dos serviços e do relacionamento continua tendo sua importância e sendo o diferencial.

\section{www.geplastic.com.br}

A GE Plastics mundial conta nos Estados Unidos, Europa, Pacífico e Brasil com grupos dedicados ao desenvolvimento de seu e-business. As atividades se iniciaram em janeiro de 1999, chegando ao Brasil em março de 2000 e, semelhante a outras empresas, a GE Plastics South America tem um grupo local multifuncional, liderado por William Juliano, que se reporta diretamente aos EUA.

Partindo da idéia de que o próprio mercado já percebeu a importância do comércio eletrônico, a GE Plastics fez da tecnologia sua filosofia e plataforma de ação e está determinada a ser um modelo de excelência de distribuição. Todos os detalhes foram exaustivamente analisados. Para a montagem do site, buscou-se um feed-back junto aos clientes, levantou-se o que era importante, juntaram-se ferramentas. À preocupação com velocidade e segurança foram somadas outras, como tempo de download das páginas e problemas de conectividade entre Brasil e Estados Unidos, o que levou inclusive ao descarte do uso da internet pública, devido ao grande tráfego de informações entre os dois países.

A experiência brasileira utilizou, de junho a agosto de 2000 , clientes-piloto especialmente convidados, aos quais foi ensinada a utilização do sistema. A aprendizagem não foi unilateral: o cliente ensinava para a empresa o que era bom ou ruim, funcionava ou não no sistema. Todo mundo estava aprendendo e somente a partir de outubro o site foi aberto ao grande público. Toda a parte burocrática passa a ser feita pelo site, com um gerenciamento muito mais rápido, de forma que o cliente receba na hora certa o produto certo e pelo preço certo. A GE joga todo o peso de seu nome no perfeito funcionamento do novo sistema e comercializa com exclusividade seus produtos. Mas a liderança se faz sentir além da colocação do pedido pelo cliente. O grupo de vendas não apenas apresenta a melhor performance, com respostas rápidas. Na busca de informações sobre novos materiais ou sobre a especificação de produtos, a GE é a primeira empresa com assistência técnica on line, fornecendo na hora as informações solicitadas pelo cliente, estejam elas disponíveis no Brasil, Estados Unidos ou Europa. É a globalização da informação.

No último dia 14 de fevereiro a GE Plastics lançou a GE Polymerland, empresa que se tornou seu braço de distribuição. $\mathrm{Na}$ América do Sul, todas as vendas da empresa, seja pelos processos convencionais ou pela internet, agora acontecem através da GE Polymerland, que não se restringe aos produtos da GE Plastics, uma vez que pretende distribuir um portfolio completo de termoplásticos. Para isso, o primeiro contrato de distribuição já foi fechado com a Rhodia.

O pioneirismo da GE Plastics está diretamente relacionado com a pergunta que precede cada iniciativa: - Isso é produtividade para o cliente? Se não for, não há por que continuar. O ganho de produtividade do cliente é o foco de todas as ações. E o resultado obtido em poucos meses parece comprovar o acerto das decisões: no ano 2000 , a nível mundial, o e-commerce foi responsável pela comercialização de US\$ 1,5 bilhão. No Brasil, a empresa comercializou US\$ 10 milhões pela web e no mês de dezembro o percentual comercializado chegou a $40 \%$ da receita mensal. Nada mal para quem está apenas começando... 


\section{Conclusão}

Avaliando rapidamente a influência da internet, é indiscutível a verdadeira revolução que causou enquanto instrumento de comunicação. Também não se discute o quanto facilitou os contatos interpessoais e o trabalho de muitos profissionais. Que o potencial de desenvolvimento ainda está longe de se esgotar é outro ponto de consenso. As facilidades e os problemas estão sendo largamente divulgados, o que tem contribuído para acalmar ânimos mais entusiasmados. A "quebra" de muitas empresas pontocom também serviu de alerta para que se tomasse mais cuidado com a sedução da internet

Da parte das empresas, algumas se mantêm reservadas na divulgação de seus projetos, evitando anunciar o que tecnologicamente parece fácil de fazer, mas que tem uma série de implicações de difícil execução. No momento atual ninguém ainda pensa em avaliar a relação custo/ benefício e nem se faz qualquer menção ao nível dos investimentos para manutenção de um site e de tudo que está agregado a ele.

O que chama a atenção é a seriedade com que a maioria das empresas está lidando com o as- sunto. Divulgar os produtos e vender pela internet é apenas um ângulo da questão. A relação com o cliente está muito valorizada e o sucesso de uma venda está diretamente ligado ao atendimento de suas necessidades. Existe todo um complexo de situações que deve ser satisfeito. As facilidades que a internet oferece e a competitividade que a globalização exige trouxeram maturidade para as empresas que agora buscam aperfeiçoar o que já foi feito e descobrir formas ainda mais eficazes de utilizar essa que pode ser a "mina de ouro" moderna: a world wide web ou simplesmente $w w w$.

Matéria elaborada por Fátima S. Cordebello, secretária executiva da ABPol. 